\title{
A score to predict short-term risk of COPD exacerbations (SCOPEX)
}

\author{
This article was published in the following Dove Press journal: \\ International Journal of COPD \\ 27 January 2015 \\ Number of times this article has been viewed
}

\section{Barry J Make' \\ Göran Eriksson ${ }^{2}$ \\ Peter M Calverley ${ }^{3}$ \\ Christine $\mathrm{R}$ Jenkins ${ }^{4}$ \\ Dirkje S Postma ${ }^{5}$ \\ Stefan Peterson ${ }^{6}$ \\ Ollie Östlund ${ }^{7}$ \\ Antonio Anzueto ${ }^{8}$}

'Division of Pulmonary Sciences and Critical Care Medicine, National Jewish Health, University of Colorado Denver School of Medicine, Denver, CO, USA; ${ }^{2}$ Department of Respiratory Medicine and Allergology, University Hospital, Lund, Sweden; ${ }^{3}$ Pulmonary and Rehabilitation Research Group, University Hospital Aintree, Liverpool, UK; ${ }^{4}$ George Institute for Global Health, The University of Sydney and Concord Clinical School, Woolcock Institute of Medical Research, Sydney, NSW, Australia; ${ }^{5}$ Department of Pulmonology, University of Groningen and GRIAC Research Institute, University Medical Center Groningen, Groningen, The Netherlands; ${ }^{6}$ StatMind AB, Lund, Sweden; ${ }^{7}$ Department of Medical Sciences and Uppsala Clinical Research Center, Uppsala University, Uppsala, Sweden; ${ }^{8}$ Department of Pulmonary/Critical Care, University of Texas Health Sciences Center and South Texas Veterans Healthcare System, San Antonio, TX, USA

Correspondence: Barry J Make National Jewish Health, 1400 Jackson Street, K729, Denver, CO, USA

$\mathrm{Tel}+\mathrm{I} 303398$ I720

Fax + I 3032702249

Email makeb@njhealth.org
Background: There is no clinically useful score to predict chronic obstructive pulmonary disease (COPD) exacerbations. We aimed to derive this by analyzing data from three existing COPD clinical trials of budesonide/formoterol, formoterol, or placebo in patients with moderate-tovery-severe COPD and a history of exacerbations in the previous year.

Methods: Predictive variables were selected using Cox regression for time to first severe COPD exacerbation. We determined absolute risk estimates for an exacerbation by identifying variables in a binomial model, adjusting for observation time, study, and treatment. The model was further reduced to clinically useful variables and the final regression coefficients scaled to obtain risk scores of $0-100$ to predict an exacerbation within 6 months. Receiver operating characteristic (ROC) curves and the corresponding C-index were used to investigate the discriminatory properties of predictive variables.

Results: The best predictors of an exacerbation in the next 6 months were more COPD maintenance medications prior to the trial, higher mean daily reliever use, more exacerbations during the previous year, lower forced expiratory volume in 1 second/forced vital capacity ratio, and female sex. Using these risk variables, we developed a score to predict short-term (6-month) risk of COPD exacerbations (SCOPEX). Budesonide/formoterol reduced future exacerbation risk more than formoterol or as-needed short-acting $\beta_{2}$-agonist (salbutamol).

Conclusion: SCOPEX incorporates easily identifiable patient characteristics and can be readily applied in clinical practice to target therapy to reduce COPD exacerbations in patients at the highest risk.

Keywords: chronic obstructive pulmonary disease, exacerbation, model, predictor, inhaled corticosteroids, bronchodilators

\section{Introduction}

Exacerbations of chronic obstructive pulmonary disease (COPD) are associated with worse health status, more depressive symptoms, and accelerated lung function decline. ${ }^{1-3}$ COPD-related hospitalizations are a major driver of health care costs, accounting for around $68 \%$ of the direct medical expenses of COPD, ${ }^{4}$ and are independently associated with a high risk of death regardless of the severity of airflow limitation..$^{5-7}$ Therefore, reducing exacerbations is an important goal in the management of COPD. ${ }^{8}$

In order to reduce future COPD exacerbations, clinicians need a clear understanding of how to predict exacerbation risk based on each patient's unique characteristics. ${ }^{9}$ The strongest predictor for COPD exacerbations is a previous history of exacerbation. ${ }^{10,11}$ Other factors that are associated with increased exacerbation risk include more severe lung disease as reflected by a lower forced expiratory volume in 1 second $\left(\mathrm{FEV}_{1}\right) \%$ predicted, ${ }^{11,12}$ 
gastroesophageal reflux disease (GERD), ${ }^{10}$ poorer quality of life (QOL) ${ }^{10}$ chronic bronchitis, ${ }^{13}$ older age, ${ }^{11}$ lower body mass index (BMI), ${ }^{11}$ depression, and anxiety. ${ }^{14}$ While these risk factors are known, there have been few attempts to integrate these findings into clinical practice. Thus, we sought to develop a clinically useful scoring system to assess short-term future exacerbation risk by analyzing easily identifiable characteristics of COPD patients. To develop this score, we used data from clinical trials evaluating the safety and efficacy of budesonide/formoterol (BUD/FORM) in patients with a prior history of exacerbations. We identified patient characteristics predicting exacerbation risk in the next 6 months and assessed the effect of treatment on exacerbation risk.

\section{Methods}

\section{Studies and populations}

The analyses used data from three double-blind, randomized, parallel-group, clinical studies of 6-12 months' duration (NCT00206154, ${ }^{15}$ NCT00206167, ${ }^{16}$ and NCT00419744 ${ }^{17}$ ). These studies investigated the efficacy of twice-daily BUD/ FORM $2 \times 160 / 4.5 \mu \mathrm{g}$ (Symbicort ${ }^{\circledR}$ metered-dose inhaler; AstraZeneca, Södertälje, Sweden), FORM $2 \times 4.5 \mu \mathrm{g}$, and placebo (a short-acting $\beta_{2}$-agonist [SABA]: salbutamol [albuterol] as needed only [ 2 puffs $\times 100 \mu \mathrm{g}]$ ) in 3,141 patients with moderate-to-very-severe COPD. The inclusion/ exclusion criteria were similar in the three studies: COPD patients aged $>40$ years, smoking history $\geq 10$ pack-years, pre-bronchodilator $\mathrm{FEV}_{1}<50 \%$ predicted, $\mathrm{FEV}_{1} /$ forced vital capacity $(\mathrm{FVC})$ ratio $<0.70$, and at least one exacerbation in the previous year. Patients with a history of asthma were excluded from all three trials, by protocol, and patients were not permitted the use of leukotriene antagonists throughout the original studies. ${ }^{15-17}$

All studies were performed in accordance with the Declaration of Helsinki, Good Clinical Practice guidelines, and applicable regulatory requirements. All patients gave written, informed consent and the studies were approved by the Review Board for Human Subjects at each center.

\section{Outcome variable}

\section{and candidate predictors}

COPD exacerbations were defined as worsening of COPD symptoms requiring treatment with oral corticosteroids and/or emergency department (ER) visit/hospitalization. Patients recorded use of oral corticosteroids, ER visits, and hospitalizations using diaries, which were collected at study visits. An exacerbation was used as the outcome to identify predictors of time to first COPD exacerbation.
Candidate predictors for increased risk of a future COPD exacerbation were selected from a range of demographic and baseline parameters. COPD maintenance medications at study entry were defined as long-acting bronchodilators (including theophylline), inhaled corticosteroids (ICS), and other daily treatments (ie, short-acting $\left[\beta_{2}\right.$-agonist or antimuscarinic] bronchodilators only). The number of maintenance medications was assigned into categories: 0 (only short-acting bronchodilators), 1 (one maintenance medication), 2 (two maintenance medications), or 3 (three or more maintenance medications). Potentially relevant self-reported comorbidities and associated treatments were recorded at baseline and were grouped as cardiac-related morbidities (ischemic cardiovascular disease and arteriosclerosis), hypertension, diabetes, depression/anxiety, and GERD. Reliever salbutamol use, symptom scores, and peak expiratory flow (PEF) were recorded twice daily in patient diaries and summarized as the mean over the last 10 days of the run-in period.

\section{Statistical analyses}

Predictors were identified using Cox regression analysis stratified by treatment and study. Univariate and multivariate models were used to describe the predictive properties of each variable individually and after adjustment for other variables in the model. Some highly correlated variables tested in the univariate model were excluded in the multivariate model, namely evening PEF, day- and night-time reliever use, St George's Respiratory Questionnaire (SGRQ) individual domain scores, ${ }^{18}$ the sum of Breathlessness, Cough, and Sputum Scale (BCSS) scores, ${ }^{19}$ and individual comorbidities. The potentially non-linear nature of the risk profile of each identified predictor for exacerbations was described with linear-tailed restricted cubic splines in univariate models, including interaction by treatment and stratification by study. $P$-values are presented without adjustment for multiplicity; a conservative limit of $P<0.001$ was adopted as indication of statistical significance.

Important predictors were identified by backward selection (BWS), ranked by $P$-value in the logistic multipleregression model. The factor with the highest $P$-value was removed and the process was iterated until all remaining $P$-values were $<0.001$. This resulted in a smaller multivariate model supporting that all variables contribute predictive information.

A simplified scoring system for the risk of an exacerbation within 6 months was constructed using predictors selected by BWS. Continuous predictors were subdivided into evenly distributed tertiles, corrected to clinically relevant cut-points; 
absolute risk estimates were obtained from a binomial model for any exacerbation during the study, adjusting for exposure time. The regression coefficients were scaled to obtain score points, to a maximum of 100 ; the response function for 6-month exacerbation risk was plotted on this scale.

To investigate the discriminatory properties of our predictors, a receiver operating characteristic (ROC) curve was plotted and the corresponding $\mathrm{C}$-index was computed for the full multivariate model, including all baseline variables, the smaller model including the selected predictors and the individual predictors: post-bronchodilator $\mathrm{FEV}_{1}$ and number of exacerbations during the previous year.

\section{Results \\ Studies and populations}

Baseline and demographic characteristics for 3,141 patients from the three studies ${ }^{15-17}$ are shown in Table 1 . As per the enrolment criteria, all patients had experienced at least one exacerbation during the previous year. Since the treatment arms were not uniform in all studies, we only included

Table I Characteristics of all patients with COPD, and by sex

\begin{tabular}{|c|c|c|c|}
\hline & $\begin{array}{l}\text { All patients } \\
(n=3, \mid 4 I)\end{array}$ & $\begin{array}{l}\text { Male } \\
(n=2,0 \mid 7)\end{array}$ & $\begin{array}{l}\text { Female } \\
(n=I, 124)\end{array}$ \\
\hline Age, years & $63.1(9.2)$ & $63.9(9.1)$ & $61.7(9.3)$ \\
\hline BMI, kg/m² & $26.7(5.8)$ & $26.6(5.3)$ & $26.9(6.8)$ \\
\hline Month since first COPD symptoms & I $30.0(85.2)$ & $127.0(86.2)$ & $124.2(83.6)$ \\
\hline \multicolumn{4}{|l|}{$\mathrm{FEV}_{1}$} \\
\hline Pre-bronchodilator, \% predicted & $34.6(10.1)$ & $33.6(10.0)$ & $36.4(10.1)$ \\
\hline Reversibility, \% predicted & $5.5(5.9)$ & $5.1(5.3)$ & $6.4(6.7)$ \\
\hline Post-bronchodilator, \% predicted & $40.1(12.2)$ & $38.7(11.8)$ & $42.8(12.5)$ \\
\hline Pre-bronchodilator $\mathrm{FEV} / \mathrm{FVC}$ ratio, \% & $47.2(10.6)$ & $46.1(10.5)$ & $49.2(10.6)$ \\
\hline \multicolumn{4}{|l|}{ COPD severity (GOLD grade), n (\%) } \\
\hline II (moderate) & $649(20.7)$ & $340(16.9)$ & $309(27.5)$ \\
\hline III (severe) & $1,770(56.4)$ & $\mathrm{I}, \mathrm{I} 59(57.5)$ & $611(54.4)$ \\
\hline IV (very severe) & $697(22.2)$ & $506(25.1)$ & $191(17.0)$ \\
\hline \multicolumn{4}{|l|}{ Exacerbations during previous year, n (\%) } \\
\hline 1 & $1,886(60.0)$ & $1,264(62.7)$ & $622(55.3)$ \\
\hline 2 & $785(25.0)$ & $486(24.1)$ & $299(26.6)$ \\
\hline 3 & $258(8.2)$ & $138(6.8)$ & $120(10.7)$ \\
\hline 4 & $120(3.8)$ & $74(3.7)$ & $46(4.1)$ \\
\hline$>4$ & $92(2.9)$ & $55(2.7)$ & $37(3.3)$ \\
\hline \multicolumn{4}{|l|}{ Smoking history } \\
\hline Median, pack-years (range) & $40.0(10.0-258.0)$ & $44.0(10.0-258.0)$ & $38.0(10.0-175.0)$ \\
\hline Current smoker, n (\%) & $\mathrm{I}, 280(40.8)$ & $772(38.3)$ & $508(45.2)$ \\
\hline Ex-smoker, $n(\%)$ & $\mathrm{I}, 86 \mathrm{I}(59.2)$ & $1,245(61.7)$ & $616(54.8)$ \\
\hline Mean SGRQ total score (range) & $55.6(6.2-100.0)$ & $54.4(6.2-100.0)$ & $57.6(10.6-100.0)$ \\
\hline Mean reliever use, inhalations per day (range) & $4.3(0.0-33.8)$ & $4.2(0.0-33.8)$ & $4.4(0.0-29.9)$ \\
\hline Sleep symptom score (0-4) & 1.04 & 1.05 & 1.01 \\
\hline \multicolumn{4}{|c|}{ Number of COPD medications at study entry, $n(\%)^{a}$} \\
\hline 0 & $803(25.6)$ & $495(24.5)$ & $308(27.4)$ \\
\hline 1 & $722(23.0)$ & $468(23.2)$ & $254(22.6)$ \\
\hline 2 & $987(31.4)$ & $622(30.8)$ & $365(32.5)$ \\
\hline 3 & $621(19.8)$ & $425(21.1)$ & $196(17.4)$ \\
\hline \multicolumn{4}{|l|}{ Comorbidities, n (\%) } \\
\hline 0 & $\mathrm{I}, \mathrm{I} 24(35.8)$ & $75 \mathrm{I}(37.2)$ & $373(33.2)$ \\
\hline 1 & $1,119(35.6)$ & $739(36.6)$ & $380(33.8)$ \\
\hline 2 & $622(19.8)$ & $374(18.5)$ & $248(22.1)$ \\
\hline$>2$ & $276(8.8)$ & $153(7.6)$ & $123(10.9)$ \\
\hline
\end{tabular}

Notes: Data reported as mean and standard deviation, unless stated otherwise. GOLD COPD grades are defined as: grade II = post-bronchodilator FEV $50 \%-80 \%$ of predicted; grade III = post-bronchodilator $\mathrm{FEV}, 30 \%-50 \%$ of predicted; and grade IV = post-bronchodilator $\mathrm{FEV},<30 \%$ of predicted. ${ }^{\text {a Number }}$ of $\mathrm{COPD}$ maintenance medications at study entry: $0=$ no maintenance treatment with LA (long-acting $\beta_{2}$-agonists, long-acting antimuscarinics, and theophylline), ICS, or other daily treatments (ie, short-acting $\left[\beta_{2}\right.$-agonist or antimuscarinic] bronchodilators only), $\mathrm{I}=$ one maintenance medication, $2=$ two maintenance medications, $3=$ three or more maintenance medications; 'bomorbidities - number of comorbidity classes (cardiac-related morbidities [ischemic cardiovascular disease and arteriosclerosis], hypertension, diabetes, depression/anxiety, gastroesophageal reflux disease). Data from. ${ }^{15-17}$

Abbreviations: COPD, chronic obstructive pulmonary disease; FEV , forced expiratory volume in I second; FVC, forced vital capacity; GOLD, Global Initiative for Chronic Obstructive Lung Disease; ICS, inhaled corticosteroids; LA, long-acting bronchodilators; SGRQ, St George's Respiratory Questionnaire. 
patients who were randomized to FORM $9 \mu \mathrm{g}$ twice daily, BUD/FORM 320/9 $\mu \mathrm{g}$ twice daily, or placebo.

\section{Predictors of severe exacerbations}

\section{Univariate analysis}

The baseline variables included in the univariate analysis to predict time to first COPD exacerbation are shown in Supplementary Table 1 (Supplementary material). Reliever short-acting bronchodilator use, lung function (pre- and postbronchodilator $\mathrm{FEV}_{1}, \mathrm{FEV}_{1} / \mathrm{FVC}$ ratio, $\mathrm{FEV}_{1}$ reversibility, and morning and evening PEF), history of exacerbations, number of COPD maintenance medications at entry, SGRQ score (total and sub-domains), Modified Medical Research Council (MMRC) dyspnea scale score, and the BCSS breathlessness score were all predictive of exacerbations. All lung function variables were predictive, with the following order of predictive significance when sorted by $P$-value (highest to lowest): $\mathrm{FEV}_{1} / \mathrm{FVC}$ ratio $>$ pre-bronchodilator $\mathrm{FEV}_{1}>$ post-bronchodilator $\mathrm{FEV}_{1}>$ morning $\mathrm{PEF}>$ evening $\mathrm{PEF}$ (all $P<0.001$ ).

\section{Multivariate analysis}

Multivariate analysis, using BWS to $P<0.001$, identified the following parameters as significant predictors of increased exacerbation risk: more COPD maintenance medications at entry, higher mean daily reliever use over the last 10 days of run-in, more exacerbations during the previous year, lower pre-bronchodilator $\mathrm{FEV}_{1} / \mathrm{FVC}$ ratio, and female sex (Table 2).

In multivariate analyses stratified for males and females, the same predictors were found for males as for the whole population (Table 2). For females, the same predictors were found as for the whole population with one exception: the number of COPD exacerbations during the previous year was not selected, while the SGRQ total score was included.

The chosen predictors were approximately linear on a log scale and showed steep curves (Supplementary Figure 1). All lung function parameters were significant predictors, but in the BWS model, only pre-bronchodilator $\mathrm{FEV}_{1} / \mathrm{FVC}$ ratio was selected because it was the most significant. If pre-bronchodilator $\mathrm{FEV}_{1} / \mathrm{FVC}$ ratio was replaced by post-bronchodilator $\mathrm{FEV}_{1}$, a similar BWS model (Supplementary Table 2) and similar exacerbation risks (Supplementary Table 3) were seen.

\section{Development of risk score for COPD exacerbations}

The score to predict short-term (6-month) risk of COPD exacerbations (SCOPEX) is shown in Table 3.

A comparison of ROC curves (Figure 1) shows that ability to discriminate between patients who will and will not have an exacerbation using the selected predictors is similar to the full multivariate model with all baseline variables and better than two commonly known individual predictors: postbronchodilator $\mathrm{FEV}_{1}$ and number of exacerbations during the

Table 2 Backwards selection model ${ }^{\mathrm{a}}$ by Cox regression analysis of predictors for moderate and severe COPD exacerbations for all patients, and by sex

\begin{tabular}{|c|c|c|c|c|c|c|}
\hline \multirow[t]{2}{*}{ Baseline variable } & \multicolumn{2}{|c|}{ All patients $(n=3,14 I)$} & \multicolumn{2}{|c|}{ Males only $(n=2,017)$} & \multicolumn{2}{|c|}{ Females only $(n=I, 124)$} \\
\hline & HR (95\% Cl) & $\begin{array}{l}\text { Overall } \\
\text { P-value }\end{array}$ & HR (95\% Cl) & $\begin{array}{l}\text { Overall } \\
\text { P-value }\end{array}$ & HR (95\% Cl) & $\begin{array}{l}\text { Overall } \\
P \text {-value }\end{array}$ \\
\hline \multicolumn{7}{|l|}{ Number of COPD maintenance medications ${ }^{b}$} \\
\hline I vs 0 & $1.18(0.98-1.43)$ & $<0.001$ & $1.11(0.86-1.42)$ & $<0.001$ & $1.33(0.99-1.77)$ & $<0.00$ I \\
\hline 2 vs 0 & $1.57(1.32-1.86)$ & & $1.64(1.31-2.06)$ & & $1.50(1.15-1.96)$ & \\
\hline 3 vs 0 & $1.91(1.59-2.30)$ & & $1.99(1.57-2.52)$ & & $1.83(1.35-2.47)$ & \\
\hline Reliever use, number of inhalations & $1.05(1.04-1.07)$ & $<0.001$ & $1.05(1.03-1.06)$ & $<0.001$ & $1.05(1.03-1.08)$ & $<0.001$ \\
\hline \multicolumn{7}{|l|}{ Number of exacerbations in the previous year } \\
\hline 2 vs I & $1.40(|.2|-\mid .6 I)$ & $<0.001$ & $1.45(|.2|-\mid .75)$ & $<0.001$ & & \\
\hline 3 vs I & $1.63(1.33-2.00)$ & & $1.74(|.3|-2.3 \mathrm{I})$ & & & \\
\hline 4 vs $I$ & $1.70(1.29-2.24)$ & & $1.97(1.40-2.79)$ & & & \\
\hline$>4$ vs I & $2.07(1.55-2.78)$ & & $2.22(1.5 \mathrm{I}-3.26)$ & & & \\
\hline SGRQ total score & & & & & $1.01(1.00-1.02)$ & $<0.001$ \\
\hline Pre-bronchodilator $\mathrm{FEV}_{1} / \mathrm{FVC}$ ratio (per $10 \%$ ) & $0.83(0.78-0.88)$ & $<0.001$ & $0.98(0.97-0.99)$ & $<0.01$ & $0.98(0.97-0.99)$ & $<0.001$ \\
\hline Sex, female vs male & $1.32(1.16-1.50)$ & $<0.001$ & & & & \\
\hline \multicolumn{7}{|c|}{ 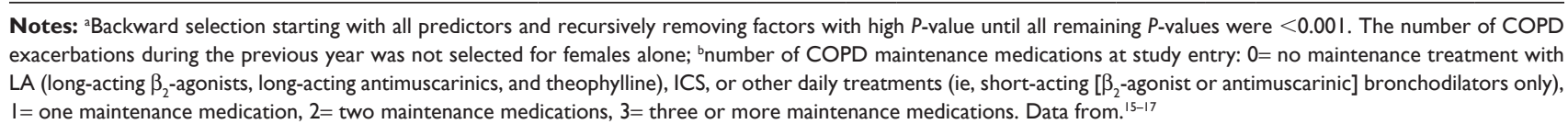 } \\
\hline \multicolumn{7}{|c|}{$\begin{array}{l}\text { Abbreviations: Cl, confidence interval; COPD, chronic obstructive pulmonary disease; FEV }, \text { forced expiratory volume in I second; FVC, forced vital capacity; HR, hazard } \\
\text { ratio; ICS, inhaled corticosteroids; LA, long-acting bronchodilator; SGRQ, St George's Respiratory Questionnaire. }\end{array}$} \\
\hline
\end{tabular}


Table 3 Risk score formula for COPD exacerbation in the next 6 months

\begin{tabular}{lc}
\hline Baseline variable & Score \\
\hline Sex & \\
Male & 10 \\
Female & \\
Number of COPD maintenance medications ${ }^{\mathrm{a}}$ & \\
$0-1$ & 12 \\
2 & 20 \\
3 & \\
Number of exacerbations in previous year & \\
1 & 13 \\
2 & 17 \\
$3-4$ & 24 \\
$>4$ & \\
FEV 1 FVC ratio & \\
$\geq 60 \%$ & 17 \\
$40 \%-59 \%$ & 25 \\
$<40 \%$ & \\
Reliever use, no of inhalations/day & \\
$<5$ & 10 \\
$5-10$ & 21 \\
$\geq 10$ & \\
\hline
\end{tabular}

Notes: ${ }^{\text {Number }}$ of COPD maintenance medications at study entry: $0=$ no maintenance treatment with LA (long-acting $\beta_{2}$-agonists, long-acting antimuscarinics, and theophylline), ICS, or other daily treatments (ie, short-acting $\left[\beta_{2}\right.$-agonist or antimuscarinic] bronchodilators only), I= one maintenance medication, $2=$ two maintenance medications, $3=$ three or more maintenance medications.

Abbreviations: $\mathrm{FEV}_{1}$, forced expiratory volume in I second; FVC, forced vital capacity; ICS, inhaled corticosteroids; LA, long-acting bronchodilator.

previous year. SCOPEX yielded a C-index of 0.67 , which is similar to the selected predictors and the full multivariate model ( 0.67 and 0.68 , respectively). The well-known individual predictors, post-bronchodilator $\mathrm{FEV}_{1}$ and number of exacerbations during the previous year, each had a C-index of 0.62.

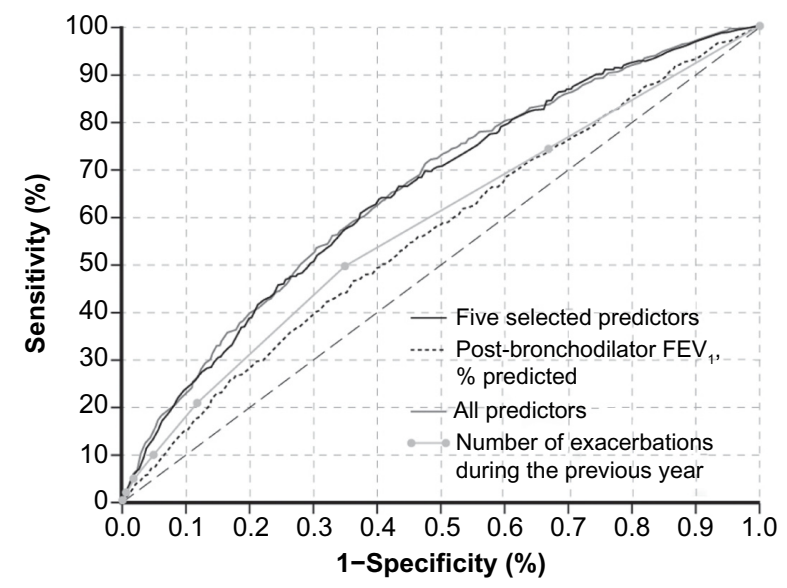

Figure I ROC curve based on the five selected predictors (C-index $=0.67$ ), the full multivariate model $(C$-index $=0.68$ ) and the individual predictors: postbronchodilator FEV $(\mathrm{C}$-index $=0.62)$ and the number of COPD exacerbations during the previous year ( $\mathrm{C}$-index $=0.62$ ).

Abbreviations: COPD, chronic obstructive pulmonary disease; $\mathrm{FEV}$, forced expiratory volume in I second; ROC, receiver operating characteristic.

\section{Effects of medications} on exacerbation risk

The 6-month exacerbation risk for a patient with a given risk score is shown in Figure 2. A higher risk score was associated with greater exacerbation risk, irrespective of randomization to placebo (ie, SABA only), FORM, or BUD/FORM. The rank order (high to low) of the 6-month exacerbation risk was: placebo $>$ FORM $>$ BUD/FORM (Figure 2) over the range of selected predictors, as seen in the spline plots (Supplementary Figure 2).

Replacing the pre-bronchodilator $\mathrm{FEV}_{1} / \mathrm{FVC}$ ratio with post-bronchodilator $\mathrm{FEV}_{1}$ led to a similar pattern of exacerbation risk across the range of risk scores (Supplementary Figure 2).

\section{Discussion}

More COPD maintenance medications, more daily SABA inhalations, more exacerbations during the previous year, worse lung function, and female sex were the best predictors of future exacerbation in this cohort of patients with moderate-to-very-severe COPD and at least one exacerbation in the previous year. Based on these readily available patient characteristics, we developed a scoring system to estimate the risk of an exacerbation over the next 6 months. This score may be applied in day-to-day clinical practice in such patients and in clinical studies to identify patients with high, medium, and low 6-month exacerbation risk. Clinicians can determine the COPD exacerbation risk score in their patients using an online calculation algorithm available at http:// nationaljewish.org/COPD-Calculator. The analysis included

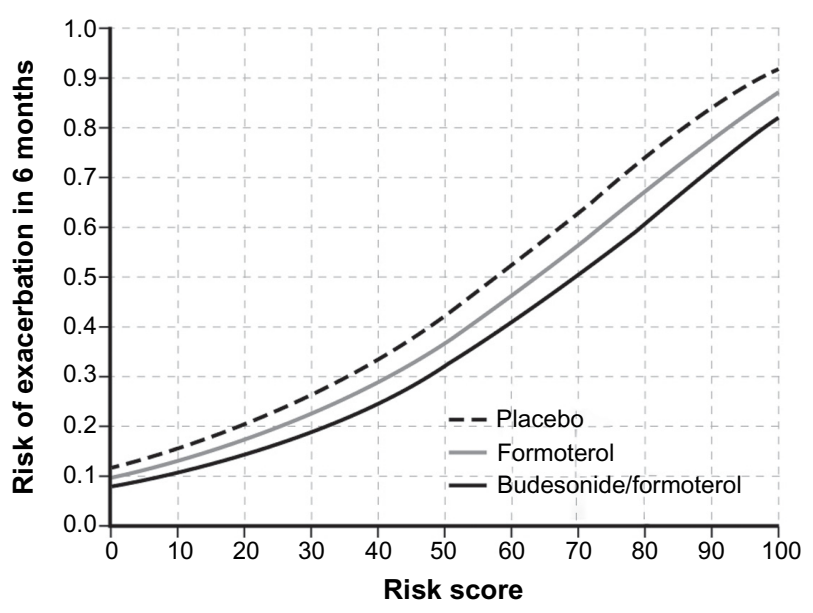

Figure 2 Risk of exacerbation in 6 months based on baseline risk score for each treatment group, with the pre-bronchodilator $\mathrm{FEV}_{1} / \mathrm{FVC}$ ratio as lung function predictor.

Abbreviations: $\mathrm{FEV}_{\mathrm{l}}$, forced expiratory volume in I second; FVC, forced vital capacity. 
interventions with multiple treatments, demonstrating that BUD/FORM treatment reduces future exacerbation risk more than FORM or as-needed SABA only.

Of the identified predictors, worse lung function $\left(\mathrm{FEV}_{1}\right)^{5,10,20-22}$ and a history of exacerbations ${ }^{10,22,23}$ are wellknown, strong predictors of a future exacerbation in broad COPD populations. Our analysis identified three more variables (number of maintenance COPD medications, sex, and daily number of short-acting bronchodilator puffs) that improved predictability in moderate-to-very-severe COPD patients. Other studies have also reported a higher exacerbation risk among female patients. ${ }^{11}$ Few studies have identified higher reliever use as a risk factor, ${ }^{21}$ likely because most clinical studies have not recorded reliever use in COPD patients. ${ }^{10}$ Finally, the total medication load as a risk factor for exacerbations is novel and has not been previously reported.

All lung function measures (pre- and post-bronchodilator $\mathrm{FEV}_{1}$, pre-bronchodilator $\mathrm{FEV}_{1} / \mathrm{FVC}$ ratio, and morning and evening PEF) were highly significantly associated with future exacerbation risk in the univariate model. Pre-bronchodilator $\mathrm{FEV}_{1} / \mathrm{FVC}$ ratio was selected in the final model, probably because of a somewhat lower variance. ${ }^{24}$ Reliever use is symptom driven and its inclusion in the model could explain why patient-related parameters such as SGRQ or daily diary symptom scores were weaker predictors of increased exacerbation risk. Our finding is in line with a correlation between reliever use loads with SGRQ and symptoms in a factorial analysis. ${ }^{25}$

Use of individual medications (eg, theophylline, ICS, and oral corticosteroids) has been reported to predict exacerbations and hospitalizations. ${ }^{22}$ To capture a patient's total respiratory medication load, we analyzed as-needed SABA only and the number of maintenance long-acting medications used at study entry. This is the first time that COPD medication load, an independent predictor of similar significance to previous exacerbations and lung function, has been reported as a predictor for exacerbations. This likely reflects physician and patient assessment and perception of symptoms, health status, exacerbation history, disease severity, and need for additional therapy.

Female sex was an important predictor of COPD exacerbations in our model. When analyzing data separately in males and females, predictors were identical to the whole population in males. In females, the multivariate analysis also included five predictors. In contrast, the SGRQ score was additionally selected in the final BWS model, whereas the number of exacerbations during the previous year was not. This sex difference confirms previous findings ${ }^{11}$ and may be related to differential symptom reporting (ie, females report worse QOL on the $\mathrm{SGRQ}^{26}$ ), increased symptom load in women, or hormonal differences.

Other patient characteristics (eg, age and BMI) did not predict exacerbations in our model. Age has been identified as a predictor of COPD exacerbations in some studies, ${ }^{10,21,22}$ but not others. ${ }^{27}$ Likewise, the ability of BMI to predict exacerbations is unclear. ${ }^{21,27}$ Our finding that age and BMI do not predict exacerbations may be related to disease severity and other features of our population. Notably, adding all other measured clinical variables did not improve the ability to predict exacerbations.

Risk scoring systems for COPD exacerbations have been proposed previously by analysis of data from several studies. 22,28,29 For example, Niewoehner et al analyzed data from a placebo-controlled clinical trial of tiotropium $(\mathrm{n}=1,829)$ and found that $\mathrm{FEV}_{1} \%$ predicted, duration of COPD, a productive cough, COPD-related antibiotic or systemic corticosteroid use in the prior year, hospitalization for COPD in the prior year, and theophylline use at baseline were predictive of a higher risk of exacerbation, with a validated C-index of 0.66; a history of prior exacerbations was not required for enrolment in this study. ${ }^{22}$ Potential limitations of this risk assessment method include its reliance on patient responses when analyzing future risk for individual patients. Briggs et al developed a validated composite index (the COPD Prognostic Index [CPI]), from a pooled analysis of data from 12 studies $(n=8,802)$ to predict risk of death, hospitalization, or exacerbation. ${ }^{28}$ They found that the overall C-statistic for use of CPI in predicting both mortality and hospitalization was 0.71 but no prediction was given for future exacerbations. The CPI includes patient-reported QOL, assessed via SGRQ or Chronic Respiratory Questionnaire (CRQ), neither of which are routinely used in primary or secondary care settings. Schembri et al analyzed data from a prospective observational study $(n=3,343)$ of patients in a community in Scotland but their model was focused on predicting short-term risk of death or hospitalization, rather than exacerbations. ${ }^{29}$ Common risk factors proposed by all scoring systems are airflow limitation and previous exacerbations. ${ }^{22,28,29}$ As with our analysis, sex was included as a variable by Briggs et $\mathrm{al}^{28}$ and Schembri et al, ${ }^{29}$ but not in the proposed scoring system by Niewoehner et al. ${ }^{22}$ However, in contrast to our analysis, Briggs et $\mathrm{al}^{28}$ and Schembri et al, ${ }^{29}$ who included a similar or greater number of patients as the present analysis, did not find sex to be a predictor of exacerbation risk. The ECLIPSE study found a significant relationship between female sex and exacerbation rates in 
univariate, but not multivariate analyses. ${ }^{10}$ The potential reasons for increased exacerbation rates in females are not clear. However, anxiety, depression, and health status are risk factors for COPD exacerbations ${ }^{30,31}$ and females with COPD appear to have higher levels of anxiety and depression..$^{32}$ COPD exacerbations are also more common during the winter months, and clinicians might consider this in patient management. ${ }^{11}$

In contrast to the studies used to develop the scoring systems described above, a history of exacerbations in the past year was an entry requirement for patients enrolled in the trials used to develop SCOPEX. As previous exacerbation history has been previously determined to be the strongest predictor of future COPD exacerbation risk, ${ }^{10,11}$ the SCOPEX scoring system provides clinicians with a more individualized approach to determining the 6-month exacerbation risk in patients who have experienced a prior exacerbation than previous models.

Our analysis was based on a large number of patients and provided a comprehensive analysis of risk factors relating to outpatient care. Nevertheless, it is important to recognize the limitations of our study. We carefully assembled our cohort from complete patient data to avoid ascertainment bias. However, predictors could be different in different COPD phenotypes (eg, patients in our analysis were not using oxygen therapy). Predictors such as the SGRQ score and symptoms may apply in a milder group of COPD patients, while previous hospitalization and comorbidities could dominate in patients with very severe disease. Our estimation of comorbidities, based on self-reported data, was not as rigorous as would be the case had these data been collected prospectively in a systematic manner or obtained from health care databases, although concurrent medications are likely to signal clinically important disease. We examined moderateto-very-severe COPD patients, but the largest group of patients had severe disease (GOLD [Global Initiative for Chronic Obstructive Lung Disease] stage III),${ }^{8}$ so our data may not be generalizable to the full spectrum of COPD patients and SCOPEX should be tested in milder COPD populations. All patients had experienced an exacerbation in the previous year, as this was one of the inclusion criteria for the original trials, which likely reduced the predictive power of previous exacerbations in this model. Additionally, data were collected from clinical trials so treatment adherence and motivation may be higher than would be seen in everyday clinical practice. The sensitivity and specificity are modest (C-index around 0.7 ) when applied to individual assessment; therefore, other clinical predictors of exacerbations should be sought to further improve the specificity and sensitivity of our scoring system. For example, we did not assess the presence of the chronic bronchitic phenotype, as this had not been identified as an exacerbation risk factor when the studies were conducted. A recent multivariate logistic regression analysis showed that pulmonary artery enlargement is associated with increased exacerbation risk. ${ }^{33}$ Other radiologic features (eg, degree of emphysema, airway wall thickness) have also been shown to predict exacerbations. ${ }^{34}$ Nevertheless, the C-index for SCOPEX shows that it is as good a predictor as a multivariate model including all baseline variables and superior to the well-established single criteria of post-bronchodilator $\mathrm{FEV}_{1}$ and the number of exacerbations in the previous year (C-index of 0.62 for each alone). Equally, the C-index is comparable with those of other tools developed for similar purposes. Until more accurate risk factors, such as specific biomarkers or radiologic features, can be identified, it seems unlikely that a higher level of predictive accuracy will be achieved with a relatively simple and easy-to-use tool such as SCOPEX. The SCOPEX risk score for future exacerbations was developed based on data from patients enrolled in clinical trials; the utility of SCOPEX should be examined in a real-world population of patients with COPD in clinical practice.

In conclusion, in patients with moderate-to-very-severe COPD and history of prior exacerbations, more exacerbations during the previous year, a lower pre-bronchodilator $\mathrm{FEV}_{1} / \mathrm{FVC}$ ratio, more maintenance respiratory medications, higher daily reliever use, and female sex were the strongest predictors for future exacerbations. Based on these variables, we developed a scoring system to estimate the 6-month exacerbation risk (available at http://nationaljewish.org/COPDCalculator). Furthermore, we showed that BUD/FORM reduces future exacerbation risk in this patient population. These results suggest that future exacerbation risk can be readily assessed in day-to-day clinical practice in moderateto-very-severe COPD patients, based on readily available clinical features. Prospective longitudinal cohort studies and randomized, controlled trials are needed to validate this risk assessment tool and scoring system to refine identification of patients at increased exacerbation risk.

\section{Acknowledgments}

The authors thank Malin Fagerås and Anders Persson of AstraZeneca R\&D, Mölndal, Sweden, and Thomas Similowski of Service de Pneumologie et Réanimation Médicale, Paris, France, for their assistance with the development of SCOPEX and this manuscript. Anna Mett of inScience 
Communications, Springer Healthcare, provided medical writing assistance, funded by AstraZeneca. This analysis and the original studies were funded by AstraZeneca.

\section{Disclosure}

The University of Groningen has received honoraria for DSP advising on the conduct and analysis of clinical trial data from AstraZeneca, Nycomed, and Teva as well as for lectures at meetings supported by AstraZeneca, Chiesi, GlaxoSmithKline, Nycomed, and Teva. The University of Groningen has also received money for research by unrestricted educational grants from AstraZeneca and Chiesi; AstraZeneca, Boehringer Ingelheim, Chiesi, GlaxoSmithKline, and Nycomed have provided support for travel to meetings.

AA is a consultant and speaker for AstraZeneca, Bayer Schering Pharma, Boehringer Ingelheim, Dey Pharma, GlaxoSmithKline, and Pfizer and has received honoraria from these companies. Educational presentations have been developed for AstraZeneca, Bayer Schering Pharma, Boehringer Ingelheim, Dey Pharma, and Pfizer. Support for travel to meetings has also been provided by AstraZeneca.

$\mathrm{CRJ}$ is a board member for AstraZeneca, Boehringer Ingelheim, GlaxoSmithKline, Merck Limited, and Novartis, and a consultant for Chiesi and AstraZeneca. Educational presentations have been developed for AstraZeneca and GlaxoSmithKline, with grants also pending for these companies. Lectures have been presented on behalf of AstraZeneca, Boehringer Ingelheim, GlaxoSmithKline, Hunter Immunology, and Novartis. Support for travel to meetings has been provided by AstraZeneca.

BJM is a board member for AstraZeneca Forest, Boehringer Ingelheim, Dey Pharma, Embryon, Johnson and Johnson, MedImmune, Novartis, Nycomed, Pfizer, and Respironics, and a consultant for Astellas and Chiesi. Clinical trial data has been reviewed for Spiration, with grants currently pending with AstraZeneca, Boehringer Ingelheim, GlaxoSmithKline, MedImmune, Nabi, Pfizer, and Sunovian. Lectures have been presented on behalf of Boehringer Ingelheim, GlaxoSmithKline, and Pfizer, with video presentations developed for Boehringer Ingelheim and questionnaires produced for UBC. Educational presentations and programs have been developed (Circulate WebMD, Creative Educational Concepts, France Foundation, Johns Hopkins University, Medscape, National Jewish Health, and Veterans Health Administration [VHA]) and BJM has been a speaker for educational programs at Abbott, the American Academy of Family Practice, the American College of Chest Physicians, the American Thoracic Society, Breathe LA, the
Cleveland Clinic, and VHA. Support for travel to meetings has also been provided by AstraZeneca.

GSE, SP, and OÖ are ex-employees of AstraZeneca and own stocks within the company.

PMC is a board member for Boehringer Ingelheim, the Department of Health Respiratory Programme Board, GlaxoSmithKline, and Nycomed. He has been a consultant for Novartis and provided expert testimony for Forest. PMC has received honoraria for advising on the conduct and analysis of clinical trial data from AstraZeneca, Boehringer Ingelheim, GlaxoSmithKline, Novartis, and Nycomed. He has also spoken at meetings supported by these companies. Support for travel to meetings has been provided by AstraZeneca.

\section{References}

1. Seemungal TA, Donaldson GC, Paul EA, Bestall JC, Jeffries DJ, Wedzicha JA. Effect of exacerbation on quality of life in patients with chronic obstructive pulmonary disease. Am J Respir Crit Care Med. 1998;157(5 Pt 1):1418-1422.

2. Quint JK, Baghai-Ravary R, Donaldson GC, Wedzicha JA. Relationship between depression and exacerbations in COPD. Eur Respir J. 2008;32(1):53-60.

3. Donaldson GC, Seemungal TA, Bhowmik A, Wedzicha JA. Relationship between exacerbation frequency and lung function decline in chronic obstructive pulmonary disease. Thorax. 2002;57(10):847-852.

4. Strassels SA, Smith DH, Sullivan SD, Mahajan PS. The costs of treating COPD in the United States. Chest. 2001;119(2):344-352.

5. Garcia-Aymerich J, Serra Pons I, Mannino DM, Maas AK, Miller DP, Davis KJ. Lung function impairment, COPD hospitalisations and subsequent mortality. Thorax. 2011;66(7):585-590.

6. McGhan R, Radcliff T, Fish R, Sutherland ER, Welsh C, Make B. Predictors of rehospitalization and death after a severe exacerbation of COPD. Chest. 2007;132(6):1748-1755.

7. Soler-Cataluña JJ, Martínez-García MA, Román Sánchez P, Salcedo E, Navarro M, Ochando R. Severe acute exacerbations and mortality in patients with chronic obstructive pulmonary disease. Thorax. 2005;60(11):925-931.

8. Global Initiative for Chronic Obstructive Lung Disease (GOLD) [webpage on the Internet]. Global Strategy for the Diagnosis, Management and Prevention of COPD 2010. Available from: http://www.goldcopd.org/guidelines-global-strategy-for-diagnosismanagement.html. Accessed August 24, 2012.

9. Postma D, Anzueto A, Calverley P, et al. A new perspective on optimal care for patients with COPD. Prim Care Respir J. 2011;20(2): 205-209.

10. Hurst JR, Vestbo J, Anzueto A, et al; Evaluation of COPD Longitudinally to Identify Predictive Surrogate Endpoints (ECLIPSE) Investigators. Susceptibility to exacerbation in chronic obstructive pulmonary disease. N Engl J Med. 2010;363(12):1128-1138.

11. Jenkins CR, Celli B, Anderson JA, et al. Seasonality and determinants of moderate and severe COPD exacerbations in the TORCH study. Eur Respir J. 2012;39(1):38-45.

12. Donaldson GC, Wedzicha JA. COPD exacerbations. 1: Epidemiology. Thorax. 2006;61(2):164-168.

13. Kim V, Han MK, Vance GB, et al; COPDGene Investigators. The chronic bronchitic phenotype of COPD: an analysis of the COPDGene Study. Chest. 2011;140(3):626-633.

14. Xu W, Collet JP, Shapiro S, et al. Independent effect of depression and anxiety on chronic obstructive pulmonary disease exacerbations and hospitalizations. Am J Respir Crit Care Med. 2008;178(9): 913-920. 
15. Tashkin DP, Rennard SI, Martin P, et al. Efficacy and safety of budesonide and formoterol in one pressurized metered-dose inhaler in patients with moderate to very severe chronic obstructive pulmonary disease: results of a 6-month randomized clinical trial. Drugs. 2008;68(14): 1975-2000.

16. Rennard SI, Tashkin DP, McElhattan J, et al. Efficacy and tolerability of budesonide/formoterol in one hydrofluoroalkane pressurized metereddose inhaler in patients with chronic obstructive pulmonary disease: results from a 1-year randomized controlled clinical trial. Drugs. 2009;69(5):549-565.

17. Sharafkhaneh A, Southard JG, Goldman M, Uryniak T, Martin UJ. Effect of budesonide/formoterol pMDI on COPD exacerbations: a doubleblind, randomized study. Respir Med. 2012;106(2):257-268.

18. Jones PW, Quirk FH, Baveystock CM. The St George's Respiratory Questionnaire. Respir Med. 1991;85 Suppl B:25-31; discussion 33-27.

19. Leidy NK, Schmier JK, Jones MK, Lloyd J, Rocchiccioli K. Evaluating symptoms in chronic obstructive pulmonary disease: validation of the Breathlessness, Cough and Sputum Scale. Respir Med. 2003;97 Suppl A: S59-S70.

20. Calverley P, Pauwels RA, Jones PW, Anderson JA, Vestbos J. The severity of airways obstruction as a determinant of treatment response in COPD. Int J Chron Obstruct Pulmon Dis. 2006;1(3):209-218.

21. Miravitlles M, Guerrero T, Mayordomo C, Sánchez-Agudo L, Nicolau F, Segú JL. Factors associated with increased risk of exacerbation and hospital admission in a cohort of ambulatory COPD patients: a multiple logistic regression analysis. The EOLO Study Group. Respiration. 2000;67(5):495-501.

22. Niewoehner DE, Lokhnygina Y, Rice K, et al. Risk indexes for exacerbations and hospitalizations due to COPD. Chest. 2007;131(1):20-28.

23. Rowe BH, Villa-Roel C, Guttman A, et al. Predictors of hospital admission for chronic obstructive pulmonary disease exacerbations in Canadian emergency departments. Acad Emerg Med. 2009;16(4): 316-324.

24. Johannessen A, Omenaas ER, Bakke PS, Gulsvik A. Implications of reversibility testing on prevalence and risk factors for chronic obstructive pulmonary disease: a community study. Thorax. 2005;60(10): 842-847.
25. Postma DS, Anzueto AR, Calverley PM, et al. Identifying COPD heterogeneity by easily measurable characteristics. Am J Respir Crit Care Med. 2011;183:A1018.

26. de Torres JP, Casanova C, Hernández C, Abreu J, Aguirre-Jaime A, Celli BR. Gender and COPD in patients attending a pulmonary clinic. Chest. 2005;128(4):2012-2016.

27. Kessler R, Faller M, Fourgaut G, Mennecier B, Weitzenblum E. Predictive factors of hospitalization for acute exacerbation in a series of 64 patients with chronic obstructive pulmonary disease. Am J Respir Crit Care Med. 1999;159(1):158-164.

28. Briggs A, Spencer M, Wang H, Mannino D, Sin DD. Development and validation of a prognostic index for health outcomes in chronic obstructive pulmonary disease. Arch Intern Med. 2008;168(1): 71-79.

29. Schembri S, Anderson W, Morant S, et al. A predictive model of hospitalisation and death from chronic obstructive pulmonary disease. Respir Med. 2009;103(10):1461-1467.

30. Laurin C, Moullec G, Bacon SL, Lavoie KL. Impact of anxiety and depression on chronic obstructive pulmonary disease exacerbation risk. Am J Respir Crit Care Med. 2012;185(9):918-923.

31. Atlantis E, Fahey P, Cochrane B, Smith S. Bidirectional associations between clinically relevant depression or anxiety and COPD: a systematic review and meta-analysis. Chest. 2013;144(3):766-777.

32. Hanania NA, Mullerova H, Locantore NW, et al; Evaluation of COPD Longitudinally to Identify Predictive Surrogate Endpoints (ECLIPSE) study investigators. Determinants of depression in the ECLIPSE chronic obstructive pulmonary disease cohort. Am J Respir Crit Care Med. 2011;183(5):604-611.

33. Wells JM, Washko GR, Han MK, et al; COPDGene Investigators; ECLIPSE Study Investigators. Pulmonary arterial enlargement and acute exacerbations of COPD. N Engl J Med. 2012;367(10):913-921.

34. Han MK, Kazerooni EA, Lynch DA, et al; COPDGene Investigators. Chronic obstructive pulmonary disease exacerbations in the COPDGene study: associated radiologic phenotypes. Radiology. 2011;261(1) 274-282.
International Journal of COPD

\section{Publish your work in this journal}

The International Journal of COPD is an international, peer-reviewed journal of therapeutics and pharmacology focusing on concise rapid reporting of clinical studies and reviews in COPD. Special focus is given to the pathophysiological processes underlying the disease, intervention programs, patient focused education, and self management protocols.

\section{Dovepress}

This journal is indexed on PubMed Central, MedLine and CAS. The manuscript management system is completely online and includes a very quick and fair peer-review system, which is all easy to use. Visit http://www.dovepress.com/testimonials.php to read real quotes from published authors. 